\title{
Laparoscopic Cholecystectomy in Cirrhotic Patients
}

\section{Marius Moraru*}

Departamentul de chirurgie, Clinica I Chirurgie, Universitatea de Medicină și Farmacie "Gr. T. Popa” lași, România

*Corresponding author: Marius Moraru, MD, First Surgical Unit, "St. Spiridon” Hospital, lași, Romania, Independeței Street, No 1, 700111 , lași, Romania, Tel: +40 (0) 2322182 72; Fax: +40 (0) 2322182 72: E-mail: marius.mmc@gmail.com

Received date: 17 November 2013, Accepted date: 16 December 2013, Published date: 9 May 2014

Copyright: @ 2014 Marius M. This is an open-access article distributed under the terms of the Creative Commons Attribution License, which permits unrestricted use, distribution, and reproduction in any medium, provided the original author(s) and source are credited.

\begin{abstract}
Background: Cholelithiasis is very common in cirrhotic patients (15-30\%), occurring 1 to 3 times more often than in general population. The presence of cirrhosis, hepatocellular failure and/or portal hypertension increases the risk of postoperative complications in any type of surgery, especially biliary.
\end{abstract}

Methods: A review of the literature over the last 8 years (2005-2013) was performed by searching the Medline database using the following keywords "Laparoscopic Cholecystectomy" and "cirrhosis". We selected 11 studies that were considered well-documented and contained comparable data. We analyze the demographics, cholecystectomy indication and duration, incidence of perioperative complications and time of hospitalization in cirrhotic and noncirrhotic patients.

Results: Analysis of the literature revealed a total of 842 cirrhotic patients that undergone laparoscopic cholecystectomy in group of 11 published studies. The incidence of acute cholecystitis as indication for LC (Laparoscopic Cholecystectomy) was extremely variable (3.6\% to $52.38 \%$ ). The ratio women to men were 1.06 : 407 patients (48.34\%) were men and 435 were women (51.66\%). Mean of mean age reported by each series was of 53.77 years (range 21-86). Child-Pugh class was reported by 10 studies for a total of 577 patients, most of them being Child-Pugh class A (443 cases, 76.78\%) and B (119 cases, $23.22 \%$ ). The average operating time of reported mean values was of 94.14 minutes. Average overall morbidity rate was of $24.87 \%$; a single study reported $75 \%$ morbidity, all other studies indicating rates of maximum $35 \%$. The length of hospital stay was of 3.47 days (range: 1.87 to 7.2$)$.

Conclusions: LC, although initially contraindicated in cirrhotic patients, has gradually replaced open cholecystectomy as standard surgical procedure. The operative risk in patients with liver disease depends on the degree of preexistent hepatic dysfunction, nature of the procedure and comorbid conditions.

Keywords: Cholelithiasis; Cirrhosis; Laparoscopic Cholecystectomy

\section{Introduction}

Cholelithiasis is very common in cirrhotic patients (15-30\%), occurring 1 to 3 times more often than in general population. Gallstones are usually small and friable due to diminished gallbladder contractility and increased bile flow and rarely migrate thus making them frequently asymptomatic. When symptoms do occur, they are similar to those accounted in general population: biliary colic, acute cholecystitis, cholangitis. Septic complications can cause cirrhosis decompensation and thus dominating the clinical picture. The presence of cirrhosis, hepatocellular failure and/or portal hypertension increases the risk of postoperative complications in any type of surgery, especially on the biliary tree. In case of cirrhosis, the indication of cholecystectomy should be particularly weighted [1-3].

Until the middle 1990s, cirrhosis with portal hypertension represented a relative or absolute contraindication for Laparoscopic Cholecystectomy (LC). Nevertheless, the clinical complications clearly associated to cholelithiasis determined surgeons to re-evaluate the use of LC in this population group of severely affected patients.

Few publications have evaluated the benefits and safety of this procedure in cirrhotic patients so far. Most of the reports published over the last 15 years advocate for the use of laparoscopy as an alternative to laparotomy in early stages of cirrhosis.

The aim of our study is to review the literature in order to analyse the demographics, cholecystectomy indication and duration, incidence of perioperative complications and time of hospitalization in cirrhotic and non-cirrhotic patients and to compare reported data to our results.

\section{Methods}

A review of the literature over the last 8 years (2005-2013) was performed by searching the Medline database using the following keywords "laparoscopic cholecystectomy" and "cirrhosis". For the current research 11 studies considered well-documented and containing comparable data were selected. Articles with few data concerning patients' characteristics, perioperative parameters and outcome were excluded.

We independently reviewed selected studies and extracted data concerning patients' characteristics (gender, age, Child Pugh class, presence of acute cholecystitis), surgical procedure details (duration, conversion rate), postoperative evolution (length of hospital stay, morbidity, mortality, liver function deterioration, sepsis, bleeding). After extraction, data were included in a database and analyzed. 


\section{Results}

Analysis of the literature revealed a total of 842 cirrhotic patients that undergone LC (Table 1). The incidence of acute cholecystitis as indication for LC was extremely variable, from $3.6 \%$ to $52.38 \%$. Four studies did not report the indication for cholecystectomy. 407 patients (48.34\%) were men and 435 were women (51.66\%). The average mean age reported by each series was of 53.77 years (21-86).

Child-Pugh class was reported by 10 studies for a total of 577 patients, most of them being Child-Pugh class A (443 cases - 76.78\%) and B (119 cases - 23.22\%). Only two studies included patients diagnosed with Child-Pugh class $\mathrm{C}$ cirrhosis (4 and 2 cases, respectively).

Operating time was mentioned in 9 studies and the mean of mean values was of 94.14 minutes. The duration of the surgical procedure was extremely variable, the lowest mean time being of 65 minutes and the highest of 132 minutes.
Global morbidity rate was of $24.87 \%$, a single study reported $75 \%$ morbidity, all other studies indicating rates of maximum 35\%. Liver function deterioration, infection (pulmonary, cutaneous, peritonitis etc.), bleeding and aggravation/new onset of ascites were responsible for the majority of postoperative complications (Table 2).

As it was revealed in the analyzed studies seven $(0.83 \%)$ of the 842 registered patients died. Two of the 3 papers reporting death in their study group included Child-Pugh class $\mathrm{C}$ patients and 5 patients belonged to this subgroup.

Mean of mean length of hospital stay was of 3.47 days (range 1.87 to 7.2 days).

Shaikh et al. [1], Pavlidis et al. [12] and Mancero et al. [13] compared laparoscopic cholecystectomy in cirrhotic versus noncirrhotic patients and reported higher conversion rates $(12.89 \%$ versus $6.5 \%$ ), longer surgery time (92.6 versus 79.95 minutes), and higher morbidity rates $(26.6 \%$ versus $6.89 \%)$.

Table 1: Preoperative and operative parameters in reviewed studies; n number of patients; CP Child Pugh class; AC Acute Cholecystitis.

\begin{tabular}{|l|l|l|l|l|l|l|l|l|l|}
\hline $\begin{array}{l}\text { Reference } \\
\text { (year) }\end{array}$ & $\mathbf{n}$ & Gender (M/F) & Age & CP A & CP B & CP C & AC & Operative time (min) & Conversion rate (\%) \\
\hline $\begin{array}{l}\text { Shaikh et al. } \\
2009[1]\end{array}$ & 20 & $3 / 17$ & 43.9 & 12 & 8 & 0 & NA & 70.2 & $2(10 \%)$ \\
\hline $\begin{array}{l}\text { Curro et al. 2005 } \\
\text { [4] }\end{array}$ & 42 & $17 / 25$ & $57(28-83)$ & 22 & 16 & 4 & $22(52.38 \%)$ & NA & $3(7.14 \%)$ \\
\hline $\begin{array}{l}\text { Quillin et al. 2013 } \\
{[5]}\end{array}$ & 94 & $47 / 47$ & $52(27.4-76.5)$ & 63 & 20 & 2 & $2(2 \%)$ & $114(54-270)$ & $10(11 \%)$ \\
\hline $\begin{array}{l}\text { Palanivelu et al. } \\
\text { 2006 [7] }\end{array}$ & 265 & $142 / 123$ & $42.6(21-86)$ & NA & NA & NA & $93(35.1 \%)$ & 65 & $2(0.75 \%)$ \\
\hline $\begin{array}{l}\text { Tayeb et al. 2008 } \\
{[8]}\end{array}$ & 30 & $9 / 21$ & $42(24-76)$ & 24 & 6 & 0 & NA & $80 \pm 26$ & $2(6.67 \%)$ \\
\hline $\begin{array}{l}\text { EL-Awadi et al. } \\
\text { 2009 [9] }\end{array}$ & 55 & $26 / 27$ & $46.49 \pm 8.6$ & 47 & 8 & 0 & $2(3.6 \%)$ & $76.13 \pm 15.13$ & $4(7.33 \%)$ \\
\hline $\begin{array}{l}\text { Delis et al. 2010 } \\
{[11]}\end{array}$ & 220 & $106 / 114$ & $58(28-83)$ & 194 & 26 & 0 & $65(29.5 \%)$ & $95(60-190)$ & $12(5.45 \%)$ \\
\hline $\begin{array}{l}\text { Leandros et al. } \\
\text { 2008 [14] }\end{array}$ & 34 & $19 / 15$ & $62(31-83)$ & 23 & 11 & 0 & $8(23.53 \%)$ & 96 & $3(8.82 \%)$ \\
\hline $\begin{array}{l}\text { Pavlidis et al. } \\
\text { 2009[15] }\end{array}$ & 38 & $14 / 24$ & $62.39 \pm 13.26$ & 29 & 9 & 0 & $7(18.42 \%)$ & NA \\
\hline $\begin{array}{l}\text { Mancero et al. } \\
\text { 2008 [16] }\end{array}$ & 30 & $18 / 12$ & 55.13 & 23 & 7 & 0 & NA & 132 \\
\hline
\end{tabular}

Table 2: Postoperative parameters in reviewed studies; LOHS Length Of Hospital Stay; LFD Liver Function Deterioration.

\begin{tabular}{|l|l|l|l|l|l|l|l|}
\hline Reference (year) & LOHS (days) & Morbidity & Mortality & LFD & Infection & Bleeding & Ascites \\
\hline Shaikh et al. 2009 [1] & $2.8 \pm 1.19$ & $15(75 \%)$ & 0 & NA & 0 & 0 & $2(10 \%)$ \\
\hline Curro et al. 2005 [4] & 7.2 & $15(35 \%)$ & $2(4.76 \%)$ & NA & NA & NA & NA \\
\hline Quillin et al. 2013 [5] & $2.6 \pm 4.3$ & $32(34 \%)$ & $4(4 \%)$ & NA & $15(15.96 \%)$ & $1(1.1 \%)$ & $6(6.38 \%)$ \\
\hline Palanivelu et al. 2006 [7] & 4 & $40(15 \%)$ & 0 & $40(15 \%)$ & $4(1.5 \%)$ & $32(12 \%)$ & $28(10.6 \%)$ \\
\hline Tayeb et al. 2008 [8] & $3 \pm 2.7$ & $7(23.33 \%)$ & 0 & $2(6.67 \%)$ & $2(6.67 \%)$ & $2(6.67 \%)$ & $1(3.33 \%)$ \\
\hline EL-Awadi et al. 2009 [9] & $1.87 \pm 1.11(1-5)$ & $7(12.73 \%)$ & 0 & $3(5.5 \%)$ & $4(7.27 \%)$ & 0 & NA \\
\hline
\end{tabular}


Citation: Marius M. Laparoscopic Cholecystectomy in Cirrhotic Patients. Journal of Surgery [Jurnalul de Chirurgie] 2014; 10(1): 11-15. doi: 10.7438/1584-9341-10-1-3

Page 13

\begin{tabular}{|l|l|l|l|l|l|l|l|}
\hline Delis et al. 2010 [11] & $4(2-9)$ & $20(11.6 \%)$ & 0 & NA & $11(5 \%)$ & $17(7.73 \%)$ & NA \\
\hline Leandros et al. 2008 [14] & $3(1-9)$ & $5(14.4 \%)$ & $1(2.94 \%)$ & NA & $1(2.94 \%)$ & $2(5.88 \%)$ & NA \\
\hline Pavlidis et al. 2009 [15] & $4.4 \pm 3.5$ & $3(7.8 \%)$ & 0 & NA & NA & $2(5.26 \%)$ & NA \\
\hline Mancero et al. 2008 [16] & 2.3 & $7(23.33 \%)$ & 0 & NA & NA & $1(3.33 \%)$ & NA \\
\hline
\end{tabular}

\section{Discussions}

Cholelithiasis in patients with cirrhosis occurs twice as often compared to the general population. LC, although initially contraindicated in cirrhotic patients, has gradually replaced open cholecystectomy as standard surgical procedure in gallstone disease. Improvement of surgical skills and equipment has gradually allowed the use of LC in previously contraindicated circumstances including cirrhosis. Patients with liver cirrhosis have generally been considered poor candidates for LC, especially those with end-stage liver disease and portal hypertension, the latter being initially regarded as contraindications to LC. The hardness of the fibrotic liver and the augmentation of the vasculature secondary to portal hypertension with a high risk for bleeding are the major operating difficulties encountered during the procedure. Over the years, the accumulating experience in LC has resulted in an increasing number of articles reporting that LC can be safely performed in cirrhotic patients.

Despite general acceptance of this procedure in Child-Pugh class A and $B$ patients nowadays, few data are available for patients diagnosed with class $\mathrm{C}$ cirrhosis. Only 2 of the 11 studies included such patients that are over-represented in mortality rate. The authors attempted LC in 3 class $\mathrm{C}$ patients and one of them needed to be converted to open surgery due to difficult exposure of Calot's triangle $[4,5]$.

Data from analyzed studies show that morbidity of cirrhotic patients that undergo LC is extremely variable, between 7.8 and $75 \%$, mostly due to infections and bleeding. In cirrhotic patients augmented perioperative blood loss is caused by a decreased production of clotting factors, a depletion of vitamin $\mathrm{K}$ stores, prolonged prothrombin time, an increased fibrinolytic activity, and thrombocytopenia.

Infections occur frequently in cirrhotic patients because of an immune-compromised state. As Lausten et al. showed in their study, there is an increase in circulating CD3 and CD4 cells and decrease in circulating tumor necrosis factor- $\alpha$ and interleukin- $1 \beta$ in cirrhotic patient that undergo LC [6]. Only 3 of the 11 reviewed studies considered liver function deterioration a complication of LC [7-9].

Liver function deterioration induced by anesthesia (drug toxicity, hepatic ischemia), impaired hepatic arterial circulation, perioperative hemorrhage, pneumoperitoneum, and traction on the liver is associated with ascites increase, renal failure (hepatorenal syndrome, circulatory dysfunction), and development of portal encephalopathy. The operative risk in patients with liver disease depends on the degree of preexistent hepatic dysfunction, nature of the procedure and comorbid conditions [10].

The operative risk should be carefully evaluated prior to surgery based on Child-Pugh and Model for End-stage Liver Disease (MELD) scoring system. MELD score may be superior to Child-Pugh class in assessing operative risk because it includes major components of the
Child-Pugh score and also a measure of renal function, serum creatinine $[11,12]$.

Contraindications for elective surgery include acute hepatitis, alcoholic hepatitis, and acute liver failure.

According to the reviewed literature the major difficulties encountered during LC in cirrhotic patients can be classified into 5 groups: adhesions with increased neo-vascularity, difficult retraction of the liver, inadequate exposure of Calot's triangle, a high-risk gallbladder bed and a high risk hilum [13-15].

In our opinion, left lobe hypertrophy and the irregular surface of the liver can hide the infundibulum and the cystic pedicle making surgical dissection more difficult. On the other hand, a hard and fix left lobe will obstruct view and interfere with the progression of instruments towards the cystic pedicle.

Conversion to open surgery is always an option if laparoscopic dissection proves difficult. Conversion rate decreased in the past 8 years to less than $10 \%$. Even if conversion determines morbidity augmentation (prolonged anesthesia, increased hemorrhage and operative time) compared to laparoscopy alone, this morbidity will still remain inferior to elective open surgery.

Operative time, conversion and morbidity rate were significantly higher in cirrhotic patients versus non-cirrhotic ones, but maintained an acceptable level in all analyzed studies and also in our group. Conversion should not be considered as a failure to achieve a difficult task, but a reflection of surgical judgment, because it is meant to prevent more serious complications.

These complications include significant bleeding or biliary tract injury, leading to deterioration of liver function and sepsis. Absolute indications for conversion are not readily controlled laparoscopically bleeding and inability to define adequately the loco-regional anatomy. Uncertainty of safety and efficiency warrants an immediate conversion to laparotomy [16-18]. Usually, in these patients an infrahepatic drain is placed, because postoperative bleeding is likely in the presence of associated coagulopathy. However postsurgical drainage of the liver bed is controversial mainly because of the concern about developing ascites and secondary infection in cirrhotic patients. The manipulation of the gallbladder during surgery and a possibly decreased function of Kupffer cells and inefficient clearing of enteric micro-organisms in the postoperative period may react as contributing factors leading to secondary infection of ascites and peritonitis. Extraneous infection of ascitic fluid following a drain insertion is partly circumvented by using a closed drainage system. Drains are usually removed in 24 to 48 hours. In the postoperative period, the patients are started orally after 6 hours, unless complications are suspected. Liver function tests are carried out after $48 \mathrm{~h}$. Patients are discharged as soon as they tolerate oral food and after the drain removal, within the ranges reported in the reviewed studies (1.87 to 7.2 days) and smaller than in case of 
elective open surgery. Patients are referred to a medical gastroenterologist for management of cirrhosis and future follow-up.

Mortality rate proved to be acceptable in analyzed articles and was mainly due to severely altered liver function, as 2 of the 3 studies reporting death in their study group included Child-Pugh class $\mathrm{C}$ patients. Mortality rates as high as $76 \%$ have been reported in patients diagnosed with class $\mathrm{C}$ cirrhosis $[2,19]$.

An extensive study performed by Teh et al. concluded that the most important predictors of mortality are severity of liver disease reflected by the MELD score, age, and comorbid conditions as determined by the American Society of Anesthesiologists (ASA) physical status classification. According to this author, ASA is the strongest predictor of 7 day postoperative mortality because it takes into accounts the cardiopulmonary function. MELD score is the strongest predictor of mortality beyond 7 days and long-term [12].

\section{Advantages of Laparoscopic Cholecystectomy}

In our opinion LC in cirrhotic patients offers several advantages over open cholecystectomy and includes the following $[1,8,9,19,20]$ :

- Reduced local complications (such as wound infection, dehiscence, and postoperative hernia) due to the minimally invasive techniques of LC.

- Inadvertent bacterial seeding and contamination of the ascites is also significantly reduced, because of the less contamination of ascetic fluid during laparoscopic approach compared to laparotomy.

- The inherent magnification during LC makes easier identification and dissection of the dilated vascular channels, allowing adoption of modified surgical procedures such as subtotal cholecystectomy.

- Cirrhotic patients who are likely to be infected with hepatitis B and $\mathrm{C}$ pose great risk of needle stick injury to the entire operating team this risk being markedly reduced during LC.

- Coagulopathy is a major problem in patients with cirrhosis with a potential risk of bleeding in open cholecystectomy with subsequent hematoma and infection; this risk might be avoided through laparoscopic approach.

- LC offers the potential for fewer right upper quadrant adhesions postoperatively, which may be beneficial during future liver transplantation.

\section{Conclusions}

Cirrhotic patients have a higher risk of perioperative complications and require optimization prior to elective surgical intervention. Patients with well compensated cirrhosis should be considered for operative intervention when they have symptoms that may be treated surgically. LC is indicated in patients with symptomatic gallbladder stones and stable liver cirrhosis (Child A and B); for these patients the method is safe and should be the standard approach. The current general consensus revealed in the literature includes: 1) Class Child Pugh A: elective surgery well tolerated; 2) Class Child Pugh B: permissible with preoperative preparation; 3) Class Child Pugh C: contraindicated.

The laparoscopic approach has significant advantages such as easy postoperatory recovery, absence of parietal complications, short admission, and rapid social and professional recovery.
LC in patients with symptomatic cholelithiasisis is an effective and safe procedure and can be electively indicated according the experience of the operating team.

\section{Acknowledgements}

The author is Ph.D. student at "Gr. T. Popa" University of Medicine and Pharmacy, First Surgical Unit, "St. Spiridon" Hospital, Iaşi. This paper is the result of the documentation undertaken during the doctoral internship.

\section{Conflict of Interests}

Author has no conflict of interests to disclose.

\section{References}

1. Shaikh AR, Muneer A (2009) Laparoscopic cholecystectomy in cirrhotic patients. JSLS 13: 592-596.

2. Bernardo WM, Aires FT (2011) Is laparoscopic cholecystectomy safe in patients with liver cirrhosis? Rev Assoc Med Bras 57: 360-361.

3. Tarcoveanu E, Bradea C, Moldoveanu R, Vasilescu A, Nistor A. Tehnica colecistectomiei laparoscopice. Jurnalul de Chirurgie (Iasi) 2009; 5(3): 274-290.

4. Currò G, Iapichino G, Melita G, Lorenzini C, Cucinotta E (2005) Laparoscopic cholecystectomy in Child-Pugh class C cirrhotic patients. JSLS 9: 311-315.

5. Quillin RC 3rd, Burns JM, Pineda JA, Hanseman D, Rudich SM, et al. (2013) Laparoscopic cholecystectomy in the cirrhotic patient: predictors of outcome. Surgery 153: 634-640.

6. Lausten SB, Ibrahim TM, El-Sefi T, Jensen LS, Gesser B, et al. (1999) Systemic and cell-mediated immune response after laparoscopic and open cholecystectomy in patients with chronic liver disease. A randomized, prospective study. Dig Surg 16: 471-477.

7. Palanivelu C, Rajan PS, Jani K, Shetty AR, Sendhilkumar K, et al. (2006) Laparoscopic cholecystectomy in cirrhotic patients: the role of subtotal cholecystectomy and its variants. J Am Coll Surg 203: 145-151.

8. Tayeb M, Khan MR, Riaz N (2008) Laparoscopic cholecystectomy in cirrhotic patients: feasibility in a developing country. Saudi J Gastroenterol 14: 66-69.

9. El-Awadi S, El-Nakeeb A, Youssef T, Fikry A, Abd El-Hamed TM, et al. (2009) Laparoscopic versus open cholecystectomy in cirrhotic patients: a prospective randomized study. Int J Surg 7: 66-69.

10. Târcoveanu E, Niculescu D, Georgescu S, Epure O, Bradea C (2005) [Conversion in laparoscopic cholecystectomy]. Chirurgia (Bucur) 100: 437-444.

11. Delis S, Bakoyiannis A, Madariaga J, Bramis J, Tassopoulos N, et al. (2010) Laparoscopic cholecystectomy in cirrhotic patients: the value of MELD score and Child-Pugh classification in predicting outcome. Surg Endosc 24: 407-412.

12. Teh SH, Nagorney DM, Stevens SR, Offord KP, Therneau TM, et al. (2007) Risk factors for mortality after surgery in patients with cirrhosis. Gastroenterology 132: 1261-1269.

13. Tarcoveanu E, Bradea C, Moldovanu R, Dimofte G, Epure O. Anatomia laparoscopica a ficatului si cailor biliare extrahepatice. Jurnalul de Chirurgie (Iasi) 2005; 1(1): 92-102.

14. Leandros E, Albanopoulos K, Tsigris C, Archontovasilis F, Panoussopoulos SG, et al. (2008) Laparoscopic cholecystectomy in cirrhotic patients with symptomatic gallstone disease. ANZ J Surg 78: 363-365.

15. Pavlidis TE, Symeonidis NG, Psarras K, Skouras C, Kontoulis TM, et al. (2009) Laparoscopic cholecystectomy in patients with cirrhosis of the liver and symptomatic cholelithiasis. JSLS 13: 342-345.

16. Mancero JM, D'Albuquerque LA, Gonzalez AM, Larrea FI, de Oliveira e Silva A (2008) Laparoscopic cholecystectomy in cirrhotic patients with 
Citation: Marius M. Laparoscopic Cholecystectomy in Cirrhotic Patients. Journal of Surgery [Jurnalul de Chirurgie] 2014; 10(1): 11-15. doi: $10.7438 / 1584-9341-10-1-3$

Page 15

symptomatic cholelithiasis: a case-control study. World J Surg 32: 267-270.

17. Flores Cortés M, Obispo Entrenas A, Docobo Durántez F, Romero Vargas E, Legupín Tubío D, et al. (2005) Laparoscopic treatment of cholelithiasis in cirrhotic patients. Rev Esp Enferm Dig 97: 648-653.

18. Laurence JM, Tran PD, Richardson AJ, Pleass HC, Lam VW (2012) Laparoscopic or open cholecystectomy in cirrhosis: a systematic review of outcomes and meta-analysis of randomized trials. HPB (Oxford) 14: $153-161$

19. Puggioni A, Wong LL (2003) A metaanalysis of laparoscopic cholecystectomy in patients with cirrhosis. J Am Coll Surg 197: 921-926.

20. Cucinotta E, Lazzara S, Melita G (2003) Laparoscopic cholecystectomy in cirrhotic patients. Surg Endosc 17: 1958-1960. 